INDUSTRIAL RELATIONS SECTION

October, 2010

\title{
Is Collective Bargaining Pareto Efficient? A Survey of the Literature
}

\author{
Nicholas Lawson \\ Princeton University
}

October 18, 2010

\begin{abstract}
It would be hard, even today, to deny that labour unions are important economic institutions, and it is this importance that makes their consequences for efficiency so substantial. Interest in the economic analysis of unions was revived in the early 1980s, in large part by a paper by Ian McDonald and Robert Solow which formalized, algebraically and graphically, ideas which were first expressed in the context of labour markets 35 years earlier by Wassily Leontief. The standard textbook model of the labour union treats the union as a conventional monopoly seller of labour, selecting the wage while the firm chooses the level of employment; McDonald \& Solow, however, drew from Leontief's work to suggest an alternative in which the firm and union negotiate to a Pareto efficient contract. Further theoretical work followed, and a still-growing empirical literature began to develop, a significant portion of it dedicated to testing McDonald \& Solow's model against the traditional labour demand curve theory. A wide variety of empirical procedures and tests have been attempted, with a diverse and contradictory range of findings; given the importance of the question of the efficiency of union contracts, an up-to-date survey of the literature may be useful in synthesizing past results and pointing the way to future research, and it is this role which the current paper will attempt to fill.
\end{abstract}




\section{Introduction}

It would be hard, even today, to deny that labour unions are highly significant economic institutions. They represent a sizable portion of the workforce in all developed countries, with union density rates in 2001 ranging from $12.8 \%$ in the United States to $85.1 \%$ in Iceland; Canada's union density rate climbed from $27.6 \%$ in 1963 to $36.6 \%$ in 1983, although it has since declined to a rate of $28.2 \%$ in $2002^{1}$. In fact, these statistics likely underestimate the importance of unions, since, in many (particularly European) countries, unions negotiate wages for many employees who are not officially members of unions ${ }^{2}$.

Clearly, unions are important, and it is this importance that makes their consequences for efficiency so substantial. The literature on the economics of trade unions is an old one, but a quiet one through most of the 20th century, until the 1980s, when interest in the economic analysis of unions was revived ${ }^{3}$. Part of the impetus for this revival was a paper in 1981 by Ian McDonald and Robert Solow which formalized, algebraically and graphically, ideas which were first expressed in the context of labour markets 35 years earlier by Wassily Leontief. The standard textbook model of the labour union treats the union as a conventional monopoly seller of labour, selecting the wage while the firm chooses the level of employment - which is equivalent to the union choosing their most preferred point on the firm's labour demand curve; (McDonald and Solow 1981), however, drew from the realization of (Leontief 1946) that such an outcome is not Pareto efficient, to suggest an alternative in which the firm and union negotiate to an outcome in which neither party could be made better off without making the other worse off.

Further theoretical work followed, and a still-growing empirical literature began to develop, a significant portion of it dedicated to testing McDonald \& Solow's model against the traditional labour demand curve theory. A wide variety of empirical procedures and tests have been attempted, with a diverse and contradictory range of findings; given the aforementioned importance of the question of the efficiency of union contracts, an up-to-date survey of the literature may be useful in synthesizing past results and pointing the way to future

\footnotetext{
${ }^{1}$ Statistics on union density are from (Trade Union Density 2004). High union density rates are much more common in Europe than anywhere else; 2001 rates include 53.6\% in Norway, 55.8\% in Belgium, 73.8\% in Denmark, $77.8 \%$ in Finland, and $78.0 \%$ in Sweden.

${ }^{2}$ See (Economic Performance 1997).

${ }^{3}$ Excellent surveys of the entire field of research into the economics of unions are provided by (Pencavel 1991) and (Kaufman 2002).
} 
research, and it is this role which the current paper will attempt to fill.

The paper is organized as follows: Section 2 outlines the basic economic theory of the two principal models of union behaviour; Section 3 surveys the literature on empirical testing between these models; and section 4 concludes.

\section{Economic Theory of the Labour Union}

It is widely acknowledged that the theoretical economic analysis of wage and employment determination in unionized labour markets originated with the work of (Dunlop 1944) ${ }^{4}$. His formulation of the problem assumes that the union is limited to choosing a point on the firm's labour demand curve ${ }^{5}$; this formed the basis of what is now commonly referred to as the Monopoly Union (MU) model, a model that would be further developed by (Fellner 1947), (Cartter 1959) and (Oswald 1982). The following two subsections will lay out, at a very aggregated level, the basic theoretical frameworks of the Monopoly Union and Efficient Bargaining models, respectively.

\subsection{The Monopoly Union Model}

In the Monopoly Union model, the union first chooses the wage, and then the firm chooses employment subject to that wage, so the situation can be modelled as a two-stage game. In what follows in this section, the basic notational approach of (McDonald and Solow 1981), with some simplifications, will be adopted.

Let $L$ represent employment and $w$ the wage. In the second stage, the firm will choose $L$ to maximize profit; let us assume that the firm has some concave revenue function $R(L)$, as a function of the employment level. The firm's profit is then $\pi=R(L)-w L$, and subject to the wage chosen by the union, the firm will choose $L$ to satisfy:

$$
\max _{L} \pi=R(L)-w L
$$

\footnotetext{
${ }^{4}$ For a detailed discussion of the history of the economic theory of labour unions, see (MaCurdy and Pencavel 1986).

${ }^{5}$ Perhaps the most cited passage from Dunlop's book states that "An economic theory of a trade union requires that the organization be assumed to maximize (or minimize) something ... But the model is not so easily constructed since the crucial question Whose wage bill? remains." Aside from the assertions by (Ross 1948) that the trade union is a political institution that is not suited to economic analysis (he claimed that "the traditional market forces are not of compelling significance under collective bargaining. Ideas of equity and justice ... move in difference channels from supply and demand"), this assessment has been widely accepted, although, as we shall see later, Dunlop's "crucial question" of what the union maximizes remains a controversial one.
} 


$$
R_{L}=w
$$

This defines the firm's labour demand curve; for any $w$ chosen by the union, the employment level $L$ that the firm will select is defined by (1). A sketch of this result can be seen in Figure 1 below.

Figure 1: Labour Demand Curve

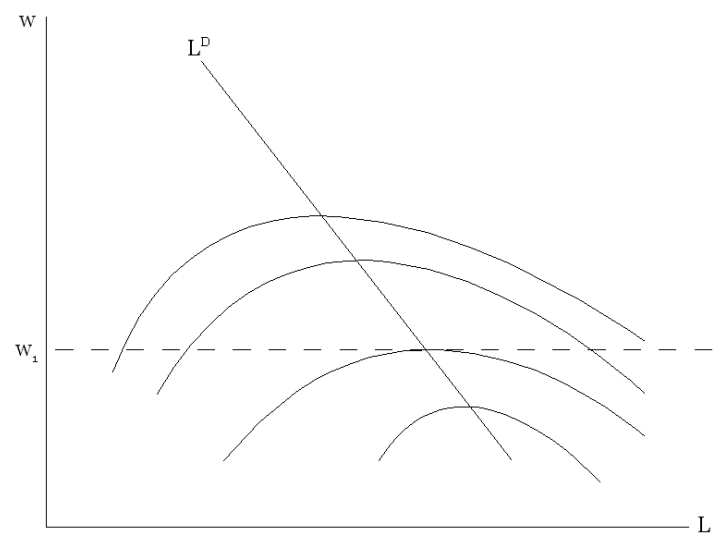

Defining the objective function of the union is, as Dunlop noted, rather more difficult. The most general way to proceed is simply to assume that the union has some utility function $U(w, L)$ (with $U_{w}, U_{L}>0$ ) over the contract wage and the level of employment; McDonald \& Solow impose greater structure on union preferences by assuming that all union members are identical, and that union utility can be expressed as the expected utility of an individual member given the probability of unemployment. Under this assumption, we can write $U(w, L)=N^{-1}[L(u(w))+(N-L) u(\bar{w})]$, where $N$ represents the membership of the union, $u(\cdot)$ is a standard concave income utility function, and $\bar{w}$ represents the generic unemployment alternative, including unemployment benefits and utility from leisure ${ }^{6}$. Since $N$ and $\bar{w}$ are, we presume, fixed for the purpose of union wage setting, we can redefine $U(w, L)=L[u(w)-u(\bar{w})]$. The union will select $w$ to maximize $U$ (however $U$ is defined); this is equivalent to choosing $w$ and $L$ subject to $R_{L}=w$ :

$$
\max _{w, L} U(w, L) \text { s.t. } R_{L}=w
$$

\footnotetext{
${ }^{6}$ This is slightly different from the notation used by McDonald \& Solow; in their initial model, they separate unemployment income from disutility of work, although they later recombine them.
} 


$$
\begin{gathered}
\mathcal{L}=U(w, L)+\lambda\left[R_{L}-w\right] \\
U_{w}-\lambda=0 \\
U_{L}+\lambda R_{L L}=0 .
\end{gathered}
$$

Therefore ${ }^{7}$ :

$$
\begin{gathered}
U_{L}+U_{w} R_{L L}=0 \\
\frac{-U_{L}}{U_{w}}=R_{L L} .
\end{gathered}
$$

Or, in the case of $U(w, L)=L[u(w)-u(\bar{w})]$ :

$$
\frac{-[u(w)-u(\bar{w})]}{L u_{w}}=R_{L L} .
$$

This result means that the union will choose the point where the firm's labour demand curve is tangent to one of their indifference curves in $(w, L)$ space, as at point A in Figure 2.

Figure 2: Tangency of Labour Demand Curve and Union Indifference Curve

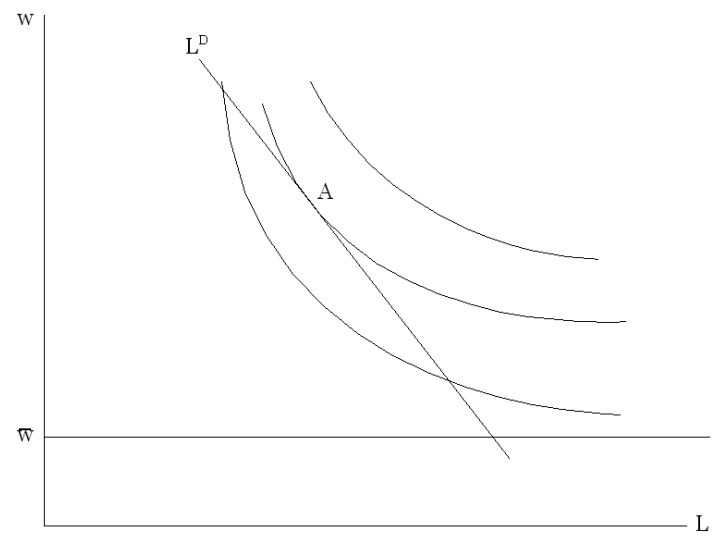

The Monopoly Union model has proven to be very popular as a description of union wage and employment outcomes, partly because the underlying game structure seems to correspond with reality; most collective bargaining processes typically do provide employers with considerable discretion over the quantity of employment ${ }^{8}$. However, the outcome of the

\footnotetext{
${ }^{7}$ Subscripts will represent first derivatives.

${ }^{8}$ This rationale for the popularity of the Monopoly Union model is identified by (MaCurdy and Pencavel 1986), among others.
} 
MU model is clearly not Pareto efficient; there are wage-employment combinations that lie off the labour demand curve which could make both firm and union better off. This was first noted, in the context of labour markets, by (Leontief 1946), and developed further by (Fellner 1947), before being given a more thorough algebraic and graphical treatment by (McDonald and Solow 1981).

Figures 1 and 2 are combined in Figure 3, allowing us to see this inefficiency graphically; the result is a region of wage-employment combinations, labelled $\mathrm{B}$, in which at least one of the firm and union can be made better off than at point A without making the other worse off. Graphically, this arises because, as Figure 1 demonstrates, the labour demand curve is defined as the locus of points at which the firm's isoprofit curve is horizontal; meanwhile, the union's indifference curve is always downward-sloping (as long as the union prefers higher employment at a given wage ${ }^{9}$ ). Pareto efficiency requires tangency of the firm's isoprofit curve and the union's indifference curve, which can never occur along the labour demand curve.

Figure 3: Inefficiency of Monopoly Union Outcome

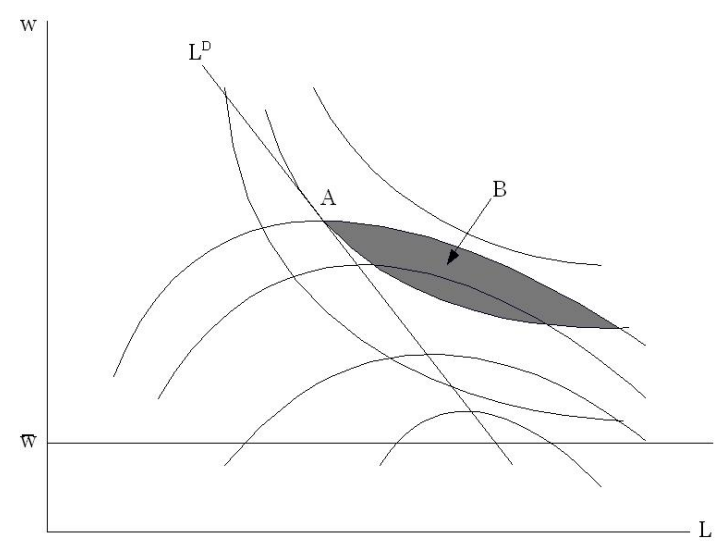

As a result, an alternative model has been developed, in which the firm and union bargain to an allocation that is Pareto efficient; the rationale for such a model is that economic agents in a one-on-one negotiation would not leave unexploited gains from trade on the table ${ }^{10}$. This

\footnotetext{
${ }^{9}$ As will be noted later, a median-voter model can result in indifference curves which are horizontal over some range, presenting the possibility that Pareto efficiency could coincide with the labour demand curve.

${ }^{10}$ (Pencavel 1991) argues that "most economists . . . are inclined to the view that union-management bar-
} 
model will be referred to as the Efficient Bargaining (EB) model, and will be outlined below.

\subsection{The Efficient Bargaining Model}

A Pareto efficient allocation of labour, as discussed above, will occur only when the isoprofit and union indifference curves are tangent to each other; in other words, when:

$$
\frac{-U_{L}}{U_{w}}=\frac{R_{L}-w}{L} .
$$

Or, in the case of $U(w, L)=L[u(w)-u(\bar{w})]$ :

$$
\frac{-[u(w)-u(\bar{w})]}{u_{w}}=R_{L}-w .
$$

This defines a locus of Pareto efficient wage-employment combinations, which, in the literature, is commonly referred to as the contract curve; it is illustrated in Figure 4. If we use McDonald \& Solow's union utility function, we can see that the contract curve will intersect the labour demand curve only at $w=\bar{w}$, because, at any point on the labour demand curve, $R_{L}-w=0$, and the left-hand side of (5) is only zero when $w=\bar{w}$. If $\bar{w}$ is the alternative wage, representing either the wage in an alternative job or the unemployment alternative (including utility from leisure), then $w=\bar{w}$ represents the competitive equilibrium (in our highly simplified partial-equilibrium model).

In Figure 4, the contract curve is drawn as upward-sloping, which is the most common depiction; however, there is no guarantee that this will be the case. In McDonald \& Solow's expected-utility formulation, the contract curve will necessarily be upward-sloping, but other union preference structures could result in a vertical contract curve, as in an earlier paper by (Hall and Lilien 1979), or even a downward-sloping curve ${ }^{11}$.

Additionally, if a collective bargaining agreement places a contract on the contract curve, the location of the point on the contract curve is not determined by the theory so far described, although numerous ways of determining the equilibrium have been proposed, the

gaining will not leave unexploited any opportunities to raise one party's welfare that do not reduce the other party's welfare." However, (Pencavel 1984) notes that this assumes the absence of transaction costs. (Fellner 1947) explains that there may be institutional obstacles preventing union and firm from reaching efficiency, such as the firm wanting to avoid the risk inherent in specifying employment in advance.

${ }^{11}$ Hall \& Lilien's vertical contract curve is a result of their assumption of zero income elasticity of labour supply; see (McDonald and Solow 1981), who also demonstrate that a downward-sloping contract curve would be the result if the union acted as a commune or family. (Brueckner 2001) analyses various cases in which we can specify which way the contract curve slopes. 
Figure 4: Contract Curve

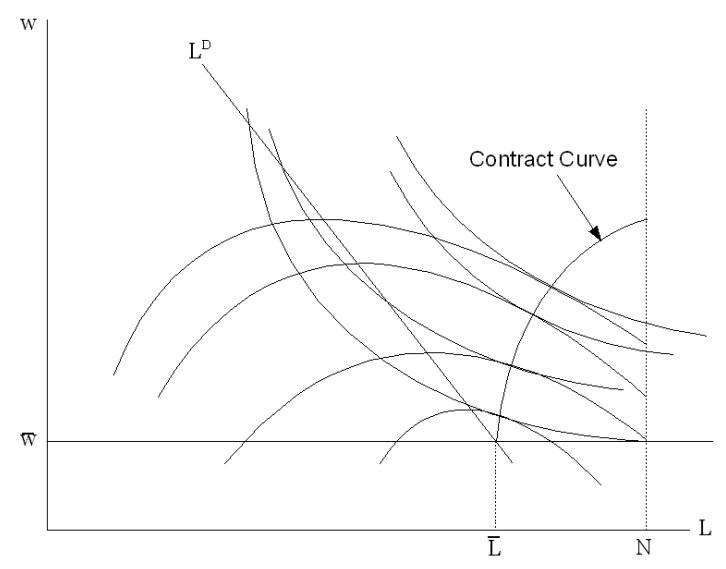

most popular of which is the asymmetric Nash bargaining solution ${ }^{12}$.

The Efficient Bargaining model draws its appeal from the fact that, unlike the Monopoly Union model, it does not imply a situation of unexploited gains from trade in a bilateral negotiation. However, the main criticism of the Efficient Bargaining model is that its fundamental structure does not appear to correspond to reality as strongly as the Monopoly Union model does; we generally do not observe firms and unions negotiating directly over the quantity of employment as well as wages (this criticism motivates the analysis of a hybrid model, that of (Kuhn 1988), in Section 3.3). On the other hand, collective bargaining does often cover issues which may proxy for employment, such as crew size, manning rules, and seniority wage structures ${ }^{13}$.

The MU and EB models represent the two most popular alternative economic representations of the wage-employment outcome of collective bargaining ${ }^{14}$, and deciding between

\footnotetext{
${ }^{12}$ (Pencavel 1991) outlines the basic idea of the asymmetric Nash bargain as being that which maximizes $(u-\bar{u})^{\alpha}(\pi-\bar{\pi})^{1-\alpha}$. Models using the two-stage collective bargaining structure proposed by (Manning 1987) generally make use of an asymmetric Nash bargain over each of wage and employment. (McDonald and Solow 1981), meanwhile, suggest a number of other possible methods of determining the equilibrium, including the existence of a dominant union or dominant firm, or some historically-determined "fair shares" division of surplus.

${ }^{13}$ (McDonald and Solow 1981) suggest that, if it is not practical to specify the level of employment in a contract, manning agreements and "featherbedding" may allow for an approximation of the efficient outcome. (Johnson 1990) and (Oswald 1993) both discuss the occurrence of such procedures in reality. However, as will be discussed later, several authors have cast doubt on the idea that bargaining over such measures can actually approximate an efficient outcome.

${ }^{14}$ Perhaps the third most popular representation is the median-voter model, which will be discussed briefly
} 
these two models is not just an issue of curiosity; there are some clear normative implications which arise from the two models. If the Monopoly Union model is correct, employment in unionized firms will be inefficiently low and wages will be too high; in a simple efficiency analysis, unions would be socially inefficient institutions and a weakening of union power would likely enhance social welfare (assuming that non-unionized labour markets are and would remain relatively competitive). If Efficient Bargaining is a better description of reality, these conclusions may not be true; if the contract curve is vertical, the employment level will be determined efficiently ${ }^{15}$, and otherwise employment will either be too high or too low for social efficiency, but will likely be less socially inefficient than the Monopoly Union outcome ${ }^{16}$. At any rate, it is certainly the case that the policy recommendations that one would make with regard to labour markets will differ depending on which model (if either) is correct. As a result of these normative considerations, a growing empirical literature has attempted to test between these two hypotheses (and others); the following section will examine the more common empirical testing procedures used, and the findings of this literature.

\section{Empirical Methodologies and Results}

This section will discuss the variety of empirical approaches which have been used to test between the MU and EB models, and the strengths and weaknesses of each approach. The first two subsections will describe, in some detail, the methodologies of the two most popular empirical approaches, as well as their results.; the third identifies a different theoretical approach which might be well suited to future empirical work, and the final subsection discusses a range of other empirical methods and their resutls.

in section 3.4. Also, numerous papers have emphasized the role of seniority beyond a simple median-voter framework, including (Frank 1985), (Kuhn 1988), and (Kuhn and Robert 1989), who analyse a simple twoworker example of (Kuhn 1988).

${ }^{15}$ However, it is possible that the quantities selected of other inputs could be inefficient; when the union raises wages about the competitive level, this could provide the firm with incentive to change their use of capital inputs, possibly to use relatively more capital due to its lower relative price. (Hirsch and Prasad 1995), however, argue that unionized firms will in fact have a lower capital-labour ratio, as unions impose what they term a "union tax on capital," since the union effectively shares in some of the quasi-rents that make up the normal return to capital. (Manning 1987) also identifies a potential for unions to cause underinvestment in capital.

${ }^{16}$ (Fellner 1947) identifies reasons why full social efficiency is unlikely to result. (Brown and Ashenfelter 1986), (Johnson 1990), and (Swanson and Andrews 2007) provide a good explanation of some of the efficiency consequences of the distinction between the MU and EB models. 


\subsection{Brown \& Ashenfelter}

The most commonly adopted empirical methodology used to test between the MU and EB models is the one initially suggested by (Brown and Ashenfelter 1986). This procedure is based on the results (1) and (4) above; if the MU hypothesis is correct, then we are on the labour demand curve, and it must be that $R_{L}=w$; if EB is correct, result (4) tells us that: $\frac{-U_{L}}{U_{w}}=\frac{R_{L}-w}{L}$, or

$$
R_{L}=w-\frac{L U_{L}}{U_{w}}
$$

Therefore, with some assumptions about the union's utility function, the Monopoly Union model can be evaluated using a nested test. This test generally involves a regression of employment on (among other things) the contract wage and the alternative wage; if the MU model is correct, the coefficient on the alternative wage will be zero, whereas, if the EB model is correct, the alternative wage will have a negative coefficient (and the contract wage will have a zero coefficient if the contract curve is vertical).

We will now outline the specific approach used by (Brown and Ashenfelter 1986). They begin by observing that a Pareto efficient contract must satisfy a condition equivalent to (6) above, which they restate as:

$$
R_{L}=w\left(1+\epsilon_{w, L}\right)
$$

where $\epsilon_{w, L}=\frac{-U_{L}}{U_{w}} \frac{L}{w}$ represents the (negative) elasticity of wages with respect to employment along the relevant union iso-utility locus. Meanwhile, a contract on the labour demand curve will satisfy the familiar condition given by (1):

$$
R_{L}=w
$$

To proceed further, some functional forms for marginal revenue product and for the union's preferences must be adopted; Brown \& Ashenfelter suggest for the workers' MRP:

$$
\log \left(R_{L}\right)=\alpha_{0}+\boldsymbol{\alpha}_{\mathbf{1}} \mathbf{X}-\alpha_{2} \log (L)
$$

where $\mathbf{X}$ represents a vector of variables that could affect MRP other than the employment level. If the MU model is correct, we can therefore substitute (8) into (9), and rearrange to obtain:

$$
\log (L)=\frac{\alpha_{0}}{\alpha_{2}}+\frac{\boldsymbol{\alpha}_{1}}{\alpha_{2}} \mathbf{X}-\frac{1}{\alpha_{2}} \log (w)
$$


In order to derive the comparable equation for the EB model, a structure for union preferences must be specified; Brown \& Ashenfelter suggest two alternatives. The first of these is a generalized Stone-Geary function ${ }^{17}$ :

$$
U(w, L)=k(w-\bar{w})^{\beta} L^{1-\beta}
$$

where $\bar{w}$ represents the union members' alternative wage. The second functional form proposed is an expected utility function of the "typical" union member, identical to that proposed by (McDonald and Solow 1981):

$$
U(w, L)=\frac{L}{N} u(w)+\left(1-\frac{L}{N}\right) u(\bar{w})
$$

where $N$ represents the total union membership, and $u(\cdot)$ is a standard concave income utility function.

Using these specifications, Brown \& Ashenfelter derive a pair of wage-employment equations, one for each utility function. However, upon estimating these equations, they find that their results are "uniformly poor," with large standard errors and parameter values that are of unexpected sign and magnitude; consequently, they decide to use a first-order approximation given by:

$$
\log (L) \approx \frac{\alpha_{0}}{\alpha_{2}}+\frac{\boldsymbol{\alpha}_{\mathbf{1}}}{\alpha_{2}} \mathbf{X}-\frac{\gamma}{\alpha_{2}} \log (\bar{w})-\frac{1-\gamma}{\alpha_{2}} \log (w) .
$$

A negative coefficient on $\log (w)$ and a statistically insignificant coefficient on $\log (\bar{w})$ would be consistent with the Monopoly Union model, while a statistically significant negative coefficient on $\log (\bar{w})$ would be consistent with Efficient Bargaining; Brown \& Ashenfelter divide this latter model into two alternatives, weak efficiency, under which there could be a significant coefficient on $\log (w)$, and strong efficiency, which requires a statistically insignificant coefficient on $\log (w)$ (strong efficiency implies the special case of a vertical contract curve). As a final addition to their model, Brown \& Ashenfelter relax the implicit assumption that unemployment union members can immediately obtain employment at the alternative wage, and include the natural logarithm of one minus the unemployment rate as a regressor. This

\footnotetext{
${ }^{17}$ The Stone-Geary specification is commonly used for union preferences, and covers a wide range of preference structures and possible hypotheses about union preferences; for example, (Andrews and Harrison 1998) note that, if $\beta=\frac{1}{2}$ (or, equivalently, if $U=k(w-\bar{w}) L$ ), a vertical contract curve would be the result of efficient bargaining. (Johnson 1990) shows that the contract curve will be negatively sloped if $\beta>\frac{1}{2}$, and positively sloped if $\beta<\frac{1}{2}$.
} 
variable, they explain, should have a negative coefficient if Efficient Bargaining is the correct model, and a zero coefficient under the Monopoly Union model.

Using data on locals belonging to the International Typographic Union during 1948-65, Brown \& Ashenfelter find some evidence in favour of the Efficient Bargaining model, but are forced to reject the hypothesis of a vertical contract curve. Their approach was also subsequently used, with alterations, by (Card 1986), (Bean and Turnbull 1988), (Gavosto 1997), and (Dimova 2006). Card, analyzing the contracts for American airline mechanics, alters Brown \& Ashenfelter's procedure to use a dynamic framework, with current alternative wages affecting future contract wages; he rejects both $\mathrm{EB}$ and MU in favour of a general contracting alternative. Bean \& Turnbull reject the MU model, and state that their evidence is more in favour of EB; however, the external validity of their findings may be limited by the source of their data, the (at the time) nationalized British coal industry in the period of 1967-83. Dimova, in an application to an economy in transition (specifically Bulgaria), finds support for weakly efficient contracts, and finally, Gavosto uses data on workers covered by the British Dock Labour Board to reject the MU model in favour of EB, and even finds strong support for a vertical contract curve.

Therefore, while the results are not generally conclusive in any direction, the majority of the papers using this empirical approach seem to provide support for the EB model, at least in the form denoted by Brown \& Ashenfelter as weak efficiency. However, a companion paper to this one, (Lawson 2009), attempts to apply the Brown \& Ashenfelter approach to a new dataset covering employment and wages in the "running trades" (conductor, engineer, brakeman, and fireman) at the Canadian Pacific Railway from 1957 to 1986; the results are typically inconclusive, but a few specifications indicate some evidence in favour of the MU model.

The Brown \& Ashenfelter empirical procedure has the virtue of simplicity, but it has come under some considerable criticism. The main concern is about the nested nature of the test; as (Martinello 1989) points out, although equations (1) and (6) are nested, the MU and EB models are inherently not nested, and there are several conditions on $U(w, L)$ which must be met for the test to work effectively ${ }^{18}$.

\footnotetext{
${ }^{18}$ Specifically, union preferences must depend on alternative wages, and alternative wages cannot be weakly separable from wages and employment in the union utility function. (Andrews and Harrison 1998) add that the MU and EB models require different sets of instrumental variables for the contract wage; they also point out that, if the union does not care about employment, the contract curve will coincide with the labour demand curve, but a nested test cannot distinguish between this possibility and a Pareto inefficient result
} 
Additionally, if the null is rejected (whichever model is treated as the null), this would normally cause us to accept the alternative hypothesis, but in this case it is not clear what the alternative hypothesis would be. A number of authors have identified reasons why the wageemployment outcome could be between the strict Monopoly Union and Efficient Bargaining outcomes $^{19}$, and if this is the case, it could be that both models are incorrect, but the Brown \& Ashenfelter procedure can only test between them.

Another complication that has arisen in some cases is that, while the theory can explain a negative or statistically insignificant coefficient on $\log (\bar{w})$, a significant positive coefficient does not seem to follow from either model; and yet this result was found by Brown \& Ashenfelter ${ }^{20}$, who were unable to identify a convincing reason for this effect. (Nickell and Wadhwani 1988) and (Nickell and Wadhwani 1991), however, argue that such a result may be indicative of efficiency wages, since a decrease in the alternative wage would lead to increased effort, which would allow the same amount to be produced with fewer workers.

Finally, Dunlop's "crucial question" of what the union maximizes remains unanswered today $^{21}$; an empirical method like Brown \& Ashenfelter's, which requires that a functional form be specified for union utility, therefore, is potentially problematic. As a result, several alternative testing procedures have been developed to meet these criticisms; the next subsection will discuss the most prominent of them.

off the contract curve.

${ }^{19}$ (Clark 1990) and (Johnson 1990) both demonstrate that bargaining measures that may appear to approximate bargaining directly over employment, such as featherbedding and agreements over crew size and work-intensity, may actually lead to outcomes that are not fully efficient. Other reasons for expecting the EB model to result in outcomes that are not Pareto efficient are discussed by (Layard and Nickell 1990), (Heywood 1993), (Manning 1994), and (Chezum and Garen 1996).

${ }^{20}$ The same result was found on one occasion by (Lawson 2009) as well.

${ }^{21}$ (Blair and Crawford 1984) demonstrate that a union's preferences, expressed through majority voting, generally will not have a von Neumann-Morgenstern representation. It is partly for this reason that numerous papers (including (Dertouzos and Pencavel 1981), (Pencavel 1984), (MaCurdy and Pencavel 1986) and (Brown and Ashenfelter 1986)) have analysed data from the International Typographical Union; Brown \& Ashenfelter suggest that problems in aggregating union preferences are less problematic when, as is the case with the ITU, union members are relatively homogenous and the union is highly democratic. An excellent survey and analysis of the difficulties of specifying and estimating union preferences is provided by (Pencavel 1985), as well as (Pencavel 1991). Empirical analysis of union preferences given a median-voter model is performed by (Farber 1978), and for a general MU model by (Dertouzos and Pencavel 1981), (Pencavel 1984) and (Carruth and Oswald 1985). 


\subsection{Alogoskoufis \& Manning}

(Manning 1987) developed a two-stage collective bargaining game to address the question of employment and wage determination. In this framework, the union and firm negotiate first over the wage, and then over employment, and the union may have different degrees of bargaining power at the two stages. This framework allows the EB and MU models to both be expressed as special cases of a more general bargaining model; if the union's employment bargaining power is $q$ and their wage bargaining power is $p$, it can be shown that the Monopoly Union model implies $p=1$ and $q=0$ (and the related "Right-ToManage" model, in which the firm sets employment but the union may not have complete power over the wage, implies $p<1$ and $q=0$ ), while the Efficient Bargaining model requires $p=q$. It is therefore possible to estimate a general bargaining equation, which nests the Monopoly Union and Efficient Bargain models as special cases and allows us to test each model against a general alternative. An additional benefit, noted by Manning, is that, if suitable proxies can be found for $p$ and $q$, it is not necessary to specify a functional form for union utility, thereby avoiding the drawback faced by models such as that of Brown \& Ashenfelter. Manning's paper, however, was purely theoretical, so this section will draw on the first attempt to use the model empirically, that of (Alogoskoufis and Manning 1991).

To begin with, the preferences of the firm and union are modelled very generally; the employer profit function is $\Pi\left(w, L ; \mathbf{X}_{\mathbf{1}}, \mathbf{X}_{\mathbf{2}}\right)$, and the union utility function is $U\left(w, L ; \mathbf{X}_{\mathbf{2}}, \mathbf{X}_{\mathbf{3}}\right)$, where $w$ is the wage, $L$ is employment, $\mathbf{X}_{\mathbf{1}}$ is a vector of variables that only affect the profit function, $\mathbf{X}_{\mathbf{2}}$ is a vector of variables that affect both profit and union utility, and $\mathbf{X}_{\mathbf{3}}$ is a vector of variables that only affect union utility. In the second stage of bargaining, after the wage has been determined, employment will be chosen to satisfy:

$$
L\left(w ; q ; \mathbf{X}_{\mathbf{1}}, \mathbf{X}_{\mathbf{2}}, \mathbf{X}_{\mathbf{3}}\right)=\arg \max _{L} \Pi\left(w, L ; \mathbf{X}_{\mathbf{1}}, \mathbf{X}_{\mathbf{2}}\right)^{(1-q)} U\left(w, L ; \mathbf{X}_{\mathbf{2}}, \mathbf{X}_{\mathbf{3}}\right)^{q}
$$

Then, moving backwards to the first stage, the wage will be chosen to satisfy:

$$
\begin{gathered}
w\left(p, q ; \mathbf{X}_{\mathbf{1}}, \mathbf{X}_{\mathbf{2}}, \mathbf{X}_{\mathbf{3}}\right)=\arg \max _{w} \Pi\left(w, L ; \mathbf{X}_{\mathbf{1}}, \mathbf{X}_{\mathbf{2}}\right)^{(1-p)} U\left(w, L ; \mathbf{X}_{\mathbf{2}}, \mathbf{X}_{\mathbf{3}}\right)^{p} \\
\text { s.t. } L=L\left(w ; q ; \mathbf{X}_{\mathbf{1}}, \mathbf{X}_{\mathbf{2}}, \mathbf{X}_{\mathbf{3}}\right)
\end{gathered}
$$

Equations (14) and (15) result in reduced-form wage and employment equations:

$$
w=w\left(p, q, \mathbf{X}_{\mathbf{1}}, \mathbf{X}_{\mathbf{2}}, \mathbf{X}_{\mathbf{3}}\right)
$$




$$
L=L\left(p, q, \mathbf{X}_{\mathbf{1}}, \mathbf{X}_{\mathbf{2}}, \mathbf{X}_{\mathbf{3}}\right) .
$$

As stated above, the MU model requires $p=1$ and $q=0$, while the EB model requires $p=q$. However, as Alogoskoufis \& Manning comment, $p$ and $q$ are likely to be unobservable in any empirical setting, so (16) and (17) must be altered before they can be used empirically. Alogoskoufis \& Manning suggest that we assume that $p$ and $q$ are functions of $\mathbf{X}_{\mathbf{4}}$, a subset of $\mathbf{X}_{1}, \mathbf{X}_{2}$, and $\mathbf{X}_{\mathbf{3}}$, and some vector $\mathbf{Z}$ of variables that do not affect profit or utility. Then, assuming that (16) and (17) are log-linear, the generalized bargaining model can be written as:

$$
\begin{aligned}
& \log (L)=\alpha_{0}+\boldsymbol{\alpha}_{\mathbf{1}} \mathbf{X}_{\mathbf{1}}+\boldsymbol{\alpha}_{\mathbf{2}} \mathbf{X}_{\mathbf{2}}+\boldsymbol{\alpha}_{\mathbf{3}} \mathbf{X}_{\mathbf{3}}+\boldsymbol{\alpha}_{\mathbf{4}} \mathbf{Z}+u_{1} \\
& \log (w)=\beta_{0}+\boldsymbol{\beta}_{\mathbf{1}} \mathbf{X}_{\mathbf{1}}+\boldsymbol{\beta}_{\mathbf{2}} \mathbf{X}_{\mathbf{2}}+\boldsymbol{\beta}_{\mathbf{3}} \mathbf{X}_{\mathbf{3}}+\boldsymbol{\beta}_{\mathbf{4}} \mathbf{Z}+u_{2}
\end{aligned}
$$

Finally, to allow for estimation by instrumental variables, Alogoskoufis \& Manning rewrite (18) and (19) in a form that allows employment to be expressed as a function of the wage, by replacing in the employment equation one of the elements of $\mathbf{Z}$, which they call $Z_{1}$ (making it necessary that there be at least two variables in $\mathbf{Z}$ ), with its solution from the wage equation:

$$
\begin{gathered}
\log (L)=\left(\alpha_{0}-\gamma \beta_{0}\right)+\left(\boldsymbol{\alpha}_{\mathbf{1}}-\gamma \boldsymbol{\beta}_{\mathbf{1}}\right) \mathbf{X}_{\mathbf{1}}+\left(\boldsymbol{\alpha}_{\mathbf{2}}-\gamma \boldsymbol{\beta}_{\mathbf{2}}\right) \mathbf{X}_{\mathbf{2}}+\left(\boldsymbol{\alpha}_{\mathbf{3}}-\gamma \boldsymbol{\beta}_{\mathbf{3}}\right) \mathbf{X}_{\mathbf{3}}+\left(\boldsymbol{\alpha}_{\mathbf{4}(\mathbf{1})}-\gamma \boldsymbol{\beta}_{\mathbf{4}(\mathbf{1})}\right) \mathbf{Z}_{(\mathbf{1})}+\gamma \log (w) \\
+\left(u_{1}-\gamma u_{2}\right) \\
\log (w)=\beta_{0}+\boldsymbol{\beta}_{\mathbf{1}} \mathbf{X}_{\mathbf{1}}+\boldsymbol{\beta}_{\mathbf{2}} \mathbf{X}_{\mathbf{2}}+\boldsymbol{\beta}_{\mathbf{3}} \mathbf{X}_{\mathbf{3}}+\boldsymbol{\beta}_{\mathbf{4}} \mathbf{Z}+u_{2}
\end{gathered}
$$

where $\mathbf{Z}$ has been partitioned into $\left(Z_{1}, \mathbf{Z}_{(\mathbf{1})}\right)$, and the parameter vectors $\alpha_{4}$ and $\beta_{4}$ into $\left(\alpha_{41}\right.$, $\left.\boldsymbol{\alpha}_{4(\mathbf{1})}\right)$ and $\left(\beta_{41}, \boldsymbol{\beta}_{\mathbf{4}(\mathbf{1})}\right)$ respectively, and $\gamma=\frac{\alpha_{41}}{\beta_{41}}$. Since $Z_{1}$ is the only additional instrument used, this is an exactly identified model.

In this framework, if the Monopoly Union model is correct, the variables in $\mathbf{X}_{\mathbf{3}}$ and $\mathbf{Z}$ only affect employment through their effect on the wage, so this implies that the coefficients on $\mathbf{X}_{\mathbf{3}}$ and $\mathbf{Z}_{(\mathbf{1})}$ in (20) should be zero. Meanwhile, if the Efficient Bargaining model is correct, then $\mathbf{X}_{\mathbf{1}}, \mathbf{X}_{\mathbf{2}}$, and $\mathbf{X}_{\mathbf{3}}$ determine the position of the contract curve, and $\mathbf{X}_{\mathbf{4}}$ and $\mathbf{Z}$ determine the point reached by collective bargaining; therefore, if the position of the contract curve is held constant and $\mathbf{Z}$ varies, the change in employment will be related to the change in the wage only through the slope of the contract curve, $\gamma$. Therefore, variables in $\mathbf{Z}$ only affect employment through their effect on the wage, which implies that the coefficients on $\mathbf{Z}_{(\mathbf{1})}$ in (20) should be zero. It is therefore straightforward to test the EB and MU models as simple F-tests of these two null hypotheses against a general alternative. 
As Alogoskoufis \& Manning point out, the employment equation implied by the MU model is a special case of that implied by the EB model, with $\mathbf{X}_{\mathbf{3}}$ excluded, which allows us to also perform a test of the MU model against the EB model; however, as they state, this suffers the same limitations as the Brown \& Ashenfelter test, in that a rejection of one model does not imply acceptance of the other.

(Alogoskoufis and Manning 1991), using data from the U.K. aggregate labour market, reject both the $\mathrm{EB}$ and $\mathrm{MU}$ models in favour of the generalized alternative bargaining model. Their two-stage bargaining game approach is used empirically by numerous other papers; (Vannetelbosch 1996), using Belgian aggregate labour market data (and a considerably more comples econometric approach), reaches a similar conclusion, rejecting the EB and Rightto-Manage models in favour of the general alternative. (Nickell and Wadhwani 1991) use a model which allows for the possibility of efficiency wages, and find that their data, from U.K. manufacturing firms, supports that interpretation. (Andrews and Harrison 1998), using data from U.K. industries, find insufficient evidence to reject either the MU or EB model - they state that, on the basis of their data, the two models "cannot be separated."

(Lawson 2009), the companion paper to the current one, also applies the Alogoskoufis \& Manning approach to the aforementioned Canadian Pacific Railway dataset; the results are once again largely inconclusive. In some specifications, both the EB and MU models can be rejected, while in others, neither can be rejected; however, the data on engineers leads to rejection of the $\mathrm{MU}$ model without simultaneous rejection of $\mathrm{EB}$, so that the paper may be interpreted as providing some evidence against MU and perhaps minimal evidence in favour of EB.

Finally, alternative non-nested equation models are suggested by (Martinello 1989), who is unable to reject either MU or EB, using data on the International Woodworkers of America and the British Columbia wood products industry, and (Christofides 1990), whose data on other Canadian industries supports a rejection of MU in favour of some form of efficient bargaining.

Therefore, as with the Brown \& Ashenfelter-style tests discussed in the previous section, contradictory and inconclusive findings have been the norm, with many papers either rejecting both the EB and MU models, or failing to reject either. The weight of the evidence is against the Monopoly Union model, with minimal support for Efficient Bargaining and substantial evidence to suggest that neither model explains the data particularly well. 


\subsection{Kuhn and Seniority Wage Profiles}

Our earlier analysis identified potential theoretical weaknesses of both the Monopoly Union and Efficient Bargaining models. The MU model leads to outcomes that are not Pareto efficient, which would seem to require the existence either of transaction costs or institutional obstacles to agreement, or irrational behaviour on one or both sides of the bargaining table; meanwhile, the EB model corresponds imperfectly to a reality in which we rarely observe direct negotiation over employment. Furthermore, the empirical findings discussed in the previous two subsections, particularly those using the Alogoskoufis \& Manning approach, indicate that neither model seems to fit perfectly with the datasets on which they have been tested. A natural question, therefore, is whether models have been proposed which combine the better features of each, allowing the firm to freely choose the quantity of employment while still achieving Pareto efficiency.

There have indeed been several models which have incorporated these characteristics. The first of these was likely that of (Hall and Lilien 1979), who demonstrate that the union, instead of only specifying a wage, could require that the total wage bill be a function of employment, in such a way that the firm's profit maximizing choice of employment would be the efficient amount. Specifically, if $R(L)$ is the firm's revenue function, and $V(L)$ is opportunity cost of labour, the efficient quantity of employment $L^{*}$ would be the one at which $R_{L}=V_{L}$; if the union sets the total wage bill as $B(L)$, they know the firm will choose the quantity of employment at which $R_{L}=B_{L}$. In that case, if the union designs the wage bill function so that $B_{L}=V_{L}$ at $L=L^{*}$, they know that the firm will choose the efficient level of employment; the firm would be free to choose any level of employment they prefer, but they would necessarily choose the efficient quantity ${ }^{22}$.

While certainly a useful attempt, Hall \& Lilien's model has some shortcomings; in particular, it assumes that the union cares about the total wage bill and not its distribution among members, or alternately that the union can make unlimited lump-sum transfers between union members. Neither of these assumptions seems entirely realistic; however, this critique was addressed by (Kuhn 1988), who proposed a model in which the union can specify a seniority wage profile. Instead of a general wage-bill function, the union specifies the wage rate for workers at each point along the seniority continuum, and requires that, if the firm

\footnotetext{
${ }^{22}$ (Martinello 1989) discusses an industry (the British Columbia wood products industry) in which such a situation may be a reality, due to the granting of many benefits which are independent of hours worked.
} 
wishes to lay off workers, they must begin with those with the lowest level of seniority; in this way, just as in (Hall and Lilien 1979), the union defines a marginal wage as a function of employment. The theory will not be discussed here, but it is not hard to show that it would be possible for the union to achieve the efficient employment outcome by setting the marginal wage equal to the opportunity cost of labour at the efficient quantity ${ }^{23}$; in effect, the union can act as a first-degree price discriminating monopolist, setting a non-linear price for labour.

Kuhn's model appears intuitively satisfying, but there do not appear to have been any previous attempts to adapt it for empirical testing. This paper's companion, (Lawson 2009), attempts to do so, by adapting the Alogoskoufis \& Manning non-nested-equation approach; the Kuhn hypothesis is rejected by most, but not all, specifications, but these results should be taken with a grain of salt, as this was neither the intended primary use of the Alogoskoufis \& Manning approach nor of the Lawson paper. We should perhaps confine ourselves simply to saying that further work seems merited on empirical testing of such a seemingly plausible and promising theoretical model.

\subsection{Alternative Empirical Methodologies}

The empirical literature on this subject has become increasingly sophisticated, and there have been a wide variety of other innovative empirical frameworks proposed. One approach to solving the difficulties of specifying a union utility function has been to treat the decisions of union leadership as the result of a median-voter process, with union members distributed along a continuum of seniority ${ }^{24}$. In such a model, as (Oswald 1993) demonstrates, union indifference curves will be flat, at least starting at the employment level of the median voter ${ }^{25}$; in practical terms, unions are indifferent to the level of employment. However, (Carruth, Oswald, and Findlay 1986) rejects the flat indifference curve hypothesis.

Among other empirical papers to address this issue, (MaCurdy and Pencavel 1986) es-

\footnotetext{
${ }^{23}$ Kuhn, however, assumes that the firm can shut down ex post and avoid any payments to the union, in which case employment will differ from first-best.

${ }^{24}$ This approach satisfies a general intuition about unions, that they care more about wages when their sector is steady or growing, and more about employment when their sector is in decline. For example, we might think that union members care only about wages when their own job is secure, but are much more concerned about preserving employment when they themselves are in danger of being laid off, as suggested in (Oswald 1993). A more general explanation of a possible shifting rate of substitution between wages and employment, using an insider-outsider approach, is presented by (Carruth and Oswald 1987).

${ }^{25}$ With flat indifference curves, (Oswald 1993) shows that the contract curve would coincide with the labour demand curve.
} 
timate production and utility functions, and compare the ratio of the marginal products of inputs to the ratio of prices; they find evidence in favour of the EB model, although they reject a vertical contract curve. (Eberts and Stone 1986) find that the difference between the union wage and the marginal revenue product is positively related to the level of employment security provisions, which they interpret as evidence in favour of the EB model. (Abowd 1989) tests whether collective bargains maximize the sum of shareholder and union wealth, and finds that, at the time of contract renegotiation, stock values move in the opposite direction from unexpected changes in labour costs, and at approximately a one-to-one rate, which is consistent with strong efficiency. (Swanson and Andrews 2007) use a stochastic cost frontier approach and find that more heavily unionized industries are more likely to operate off their labour demand curve, a result that is inconsistent with the MU model. (Wessels 1991) tests whether employment at unionized firms is higher, for a given wage, than that suggested by that firm's estimated labour demand curve, and finds that only certain specifications of his model support this hypothesis.

Finally, a somewhat unique representation of the collective bargaining process is that of (Espinosa and Rhee 1989), who model it as a dynamic repeated game. In this model, in each period, the union first chooses the wage, and then the firm chooses employment; then the game repeats in subsequent periods. In spite of the Monopoly Union structure of the game (at least in the static sense), this framework can result in a cooperative steadystate equilibrium somewhere between those predicted by the Monopoly Union and Efficient Bargaining models; if discount rates are low enough, full efficiency may even be supported as an equilibrium. (de la Rica and Espinosa 1997) test between the static (Monopoly Union and Efficient Bargain) models and the dynamic framework, and find that a generalized dynamic model is supported by their data.

\section{Conclusions}

This paper has surveyed and analysed the theoretical and empirical literature on the wageemployment outcomes of collective bargaining. We have identified a variety of empirical approaches used to test the main hypotheses, many of which fit into two main categories, those inspired by, or in the style of, (Brown and Ashenfelter 1986), or (Alogoskoufis and Manning 1991). Those in the former category tend to support the EB model over the MU 
model, whereas papers in the latter category, designed to meet criticisms levelled at the Brown \& Ashenfelter approach, are more equivocal in their findings, with some providing limited support for EB and others rejecting both models or failing to reject anything. There are other empirical papers which are hard to fit into either category, and despite their differences in approach, they tend to provide evidence in favour of EB and against MU.

Therefore, if pressed to take any final conclusions from our survey, we would say that the Monopoly Union model fares quite poorly in the empirical literature. We must allow for the possibility that different industries, and different unions, behave differently, but the weight of the evidence seems to suggest that Efficient Bargaining may be a reasonable approximation in some cases, whereas in many and perhaps most cases, some other explanation not easily categorized into the two models we have examined may be superior. A promising line of future research, it would seem, lies in developing econometric approaches to allow us to test more recent and hopefully more realistic models of union wage-employment negotiation, such as that outlined by (Kuhn 1988), in the hopes of providing further insight into a question which remains a highly important one in the field of labour economics. 


\section{References}

Abowd, J. M. (1989): "The Effect of Wage Bargains on the Stock Market Value of the Firm," American Economic Review, 79(4), 774-800.

Alogoskoufis, G., And A. Manning (1991): "Tests of Alternative Wage Employment Bargaining Models with an Application to the UK Aggregate Labour Market," European Economic Review, 35(1), 23-37.

Andrews, M., And A. Harrison (1998): "Testing for Efficient Contracts in Unionized Labour Markets," Bulletin of Economic Research, 50(3), 171-200.

Bean, C., And P. Turnbull (1988): "Employment in the British Coal Industry: A Test of the Labour Demand Model," Economic Journal, 98(393), 1092-1104.

Blair, D. H., And D. L. Crawford (1984): "Labor Union Objectives and Collective Bargaining," Quarterly Journal of Economics, 99(3), 547-566.

Brown, J. N., And O. Ashenfelter (1986): "Testing the Efficiency of Employment Contracts," Journal of Political Economy, 94(3, part 2), S40-S87.

Brueckner, J. M. (2001): "Prior Restrictions on Bargaining Contract Curves," Economics Bulletin, 10(1), 1-7.

CARD, D. (1986): "Efficient Contracts with Costly Adjustment: Short-Run Employment Determination for Airline Mechanics," American Economic Review, 76(5), 1045-1071.

(1990): "Unexpected Inflation, Real Wages, and Employt

Carruth, A., A. J. Oswald, and L. Findlay (1986): "A Test of a Model of Trade Union Behaviour: The Coal and Steel Industries in Britain," Oxford Bulletin of Economics and Statistics, 48(1), 1-18.

Carruth, A. A., and A. J. Oswald (1985): "Miners' Wages in Post-War Britain: An Application of a Model of Trade Union Behaviour," Economic Journal, 95(380), 10031020.

- (1987): "On Union Preferences and Labour Market Models: Insiders and Outsiders," Economic Journal, 97(386), 431-445.

Cartter, A. M. (1959): Theory of Wages and Employment. Richard D. Irwin Inc., Homewood, Illinois.

Chezum, B., And J. Garen (1996): "A Model of Monopoly and "Efficient" Unions with Endogenous Union Coverage: Positive and Normative Implications," Journal of Labor Research, 17(3), 497-513.

Christofides, L. N. (1990): "Non-Nested Tests of Efficient Bargain and Labour Demand Models," Economics Letters, 32(1), 91-96. 
Clark, A. (1990): "Efficient Bargains and the McDonald-Solow Conjecture," Journal of Labor Economics, 8(4), 502-528.

DE LA RicA, S., And M. P. Espinosa (1997): "Testing Employment Determination in Unionised Economies as a Repeated Game," Scottish Journal of Political Economy, 44(2), $134-152$.

Dertouzos, J. N., And J. H. Pencavel (1981): "Wage and Employment Determination under Trade Unionism: The International Typographic Union," Journal of Political Economy, 89(6), 1162-1181.

Dimova, R. (2006): "Monopolistic Wages or Efficient Contracts? What Determined the Wage-Employment Bargain in Post-Privatization Bulgaria?," Economics of Transition, $14(2), 321-347$.

Dunlop, J. T. (1944): Wage Determination Under Trade Unions. Macmillan, New York.

Eberts, R. W., and J. A. Stone (1986): "On the Contract Curve: A Test of Alternative Models of Collective Bargaining," Journal of Labor Economics, 4(1), 66-81.

Economic Performance (1997): "Economic Performance and the Structure of Collective Bargaining," in OECD Employment Outlook 1997. Organisation for Economic Co-operation and Development, at http://www.oecd.org/dataoecd/19/60/2080431.pdf.

Espinosa, M. P., And C. RheE (1989): "Efficient Wage Bargaining as a Repeated Game," Quarterly Journal of Economics, 104(3), 565-588.

FArber, H. S. (1978): "Individual Preferences and Union Wage Determination: The Case of the United Mine Workers," Journal of Political Economy, 86(5), 923-942.

Fellner, W. (1947): "Prices and Wages Under Bilateral Monopoly," Quarterly Journal of Economics, 61(4), 503-532.

Frank, J. (1985): "Trade Union Efficiency and Overemployment With Seniority Wage Scales," Economic Journal, 95(380), 1021-1034.

Gavosto, A. (1997): "The British Docks: A Test of Alternative Models of Wage and Employment Determination," Labour, 11(2), 225-248.

Green, J., And C. M. Kahn (1983): "Wage-Employment Contracts," Quarterly Journal of Economics, 98(supplement), 173-187.

Grossman, G. M. (1983): "Union Wages, Temporary Layoffs, and Seniority," American Economic Review, 73(3), 277-290.

Hall, R. E., And D. M. Lilien (1979): "Efficient Wage Bargains under Uncertain Supply and Demand," American Economic Review, 69(5), 868-879.

Heywood, J. S. (1993): "Efficient Labour Bargains, Unemployment and Non-Union Wages: A Two Sector Model," Australian Economic Papers, 32(61), 214-230. 
Hirsch, B. T., and K. Prasad (1995): "Wage-employment Determination and a Union Tax on Capital: Can Theory and Evidence be Reconciled?," Economics Letters, 48(1), $61-71$.

Johnson, G. E. (1990): "Work Rules, Featherbedding and Pareto-optimal UnionManagement Bargaining," Journal of Labor Economics, 8(1), S237-S259.

Kaufman, B. E. (2002): "Models of Union Wage Determination: What Have We Learned Since Dunlop and Ross?," Industrial Relations, 41(1), 110-158.

Kunn, P. (1988): "A Nonuniform Pricing Model of Union Wages and Employment," Journal of Political Economy, 96(3), 473-508.

Kuhn, P., and J. Robert (1989): "Seniority and Distribution in a Two-Worker Trade Union," Quarterly Journal of Economics, 104(3), 485-505.

Lawson, N. (2009): "Is Collective Bargaining Pareto Efficient? An Empirical Investigation," unpublished paper.

Layard, R., ANd S. Nickell (1990): "Is Unemployment Lower if Unions Bargain Over Employment?," Quarterly Journal of Economics, 105(3), 773-787.

Leontief, W. (1946): "The Pure Theory of the Guaranteed Annual Wage Contract," Journal of Political Economy, 54(1), 76-79.

MaCurdy, T. E., and J. H. Pencavel (1986): "Testing between Competing Models of Wage and Employment Determination in Unionized Markets," Journal of Political Economy, 94(3, part 2), S3-S39.

Manning, A. (1987): "An Integration of Trade Union Models in a Sequential Bargaining Framework," Economic Journal, 97(385), 121-139.

(1994): "How Robust is the Microeconomic Theory of the Trade Union?," Journal of Labor Economics, 12(3), 430-459.

Martinello, F. (1989): "Wage and Employment Determination in a Unionized Industry: The IWA and the British Columbia Wood Products Industry," Journal of Labor Economics, 7(3), 303-330.

McDonald, I. M., And R. M. Solow (1981): "Wage Bargaining and Employment," American Economic Review, 71(5), 896-908.

Nickell, S., and S. Wadhwani (1988): "Unions, Wages and Employment: Tests Based on U.K. Firm-Level Data," European Economic Review, 32(2-3), 727-733.

(1991): "Employment Determination in British Industry: Investigations Using Micro-Data," Review of Economic Studies, 58(5), 955-969.

Oswald, A. J. (1982): "The Microeconomic Theory of the Trade Union," Economic Journal, 92(367), 576-595. 
(1993): "Efficient Contracts are on the Labour Demand Curve: Theory and Facts," Labour Economics, 1(1), 85-113.

Pencavel, J. H. (1984): "The Tradeoff Between Wages and Employment in Trade Union Objectives," Quarterly Journal of Economics, 99(2), 215-231.

(1985): "Wages and Employment under Trade Unionism: Microeconomic Models and Macroeconomic Applications," Scandinavian Journal of Economics, 87(2), 197-225.

(1991): Labor Markets Under Trade Unionism: Employment, Wages and Hours. Blackwell, Oxford.

Ross, A. M. (1948): Trade Union Wage Policy. University of California Press, Berkeley.

Swanson, J., And K. Andrews (2007): "Testing the Monopoly Union Model: A Stochastic Frontier Approach," Industrial Relations, 46(4), 781-798.

Trade Union Density (2004): "Trade Union Density in OECD Countries 1960-2002," Organisation for Economic Co-operation and Development, at http://www.oecd.org/ dataoecd/25/42/39891561.xls.

Vannetelbosch, V. V. (1996): "Testing Between Alternative Wage-Employment Bargaining Models Using Belgian Aggregate Data," Labour Economics, 3(1), 43-64.

Wessels, W. J. (1991): "Do Unions Contract For Added Employment?," Industrial and Labor Relations Review, 45(1), 181-193. 